\title{
Sistem Informasi Distribusi Produk Paint Otomotif Menggunakan Metode DRP (Distribution Requirements Planning) Berbasis Web (Studi Kasus: CV. Catur Pandawa Maju Bersama Palembang)
}

Selly Yuliarti ${ }^{1}$, Ruliansyah ${ }^{2}$, Irfan Dwi Jaya ${ }^{3}$

sellyyuliarti@gmail.com ${ }^{1}$, ruli@ radenfatah.ac.id ${ }^{2}$,irfan_dj@ radenfatah.ac.id $^{3}$

${ }^{1}$ Prodi Sistem Informasi, Fakultas Sains dan Teknologi, UIN Raden Fatah Palembang
${ }^{2}$ Prodi Sistem Informasi, Fakultas Sains dan Teknologi, UIN Raden Fatah Palembang
${ }^{3}$ Prodi Sistem Informasi, Fakultas Sains dan Teknologi, UIN Raden Fatah Palembang

Diterima: 5 Juli 2017 | Direvisi: 26 Juli 2017 | Disetujui: 12 September 2017

(C) 2017 Program Studi Sistem Informasi Fakultas Sains dan Teknologi,

Universitas Islam Negeri Raden Fatah Palembang, Indonesia

\begin{abstract}
Abstrak: CV. Catur Pandawa Maju Bersama merupakan perusahaan yang bergerak di bidang bisnis retail thinner dan cat yang aktivitas perusahaan mencakup penjualan thinner dan cat, baik secara tunai maupun kredit. Prosedur penjualan cash lebih sederhana dibandingkan penjualan secara kredit. Karena prosedur penjualan secara cash semua transaksi dilakukan langsung di perusahaan tersebut. Permasalahan yang terjadi pada sistem yang sedang berjalan yaitu belum sepenuhnya menggunakan fasilitas teknologi informasi untuk lebih mempermudah proses pendistribusian dan dalam proses pembelian masih dilakukan dengan cara pencatatan ke buku seperti data pemasukan dan pengeluaran barang berupa nota dalam proses distribusi. Metode perhitungan yang digunakan DRP (Distribution Requirement Planning) dan menggunakan perancangan Data Flow Diagram (DFD), metode pengembangan sistem waterfall, dan menggunakan bahasa pemrograman PHP. Data yang diolah pada sistem distribusi berupa data yaitu: data jenis barang, data salesman, data toko, data harga toko, data stok barang (barang masuk dan barang keluar) dan laporan yang dihasilkan berupa laporan penjualan, keuangan, dan stok barang. Sistem ini dibangun dapat mempermudah pihak $C V$. Catur Pandawa Maju Bersama dalam melakukan kegiatan distribusi produk paint otomotif.
\end{abstract}

Kata Kunci: Sistem Informasi DRP, PHP, DFD

Abstract: CV. Catur Pandawa Maju Bersama is a company engaged in the retail thinner and paint business whose activities include selling thinner and paint, both in cash and credit. The procedure for cash sales is simpler than credit sales. Because the cash sales procedure all transactions are carried out directly at the company. The problems that occur in the current system are not yet fully using information technology facilities to facilitate the distribution process and in the purchasing process is still done by recording to books such as data entry and expenditure of goods in the form of notes in the distribution process. The calculation method used is DRP (Distribution Requirement Planning) and uses the design of Data Flow Diagrams (DFD), the method of developing the Waterfall System, and using the PHP programming language. Data processed in the distribution system is in the form of data, namely: item type data, salesman data, store data, store price data, stock data (incoming and outgoing goods) and reports produced in the form of sales, financial, and inventory items. This system is built to facilitate the CV. Catur Pandawa Maju Bersama in conducting automotive paint product distribution activities.

Keywords: DRP Information System, PHP, DFD

\section{PENDAHULUAN}

Era informasi saat ini penggunaan teknologi informasi merupakan sistem utama bagi perusahaan dalam rangka meningkatkan kinerja sistem informasi. Dengan sarana teknologi 
informasi yang memadai dan sedang menjamur saat ini, dengan salah satunya menggunakan web. Maka diharapkan segala kebutuhan akan informasi yang vital dapat terpenuhi guna mencapai tujuan utama dari instansi lembaga yang bersangkutan. CV. Catur Pandawa Maju Bersama merupakan salah satu perusahaan yang menyelenggarakan pengelolaan usaha industri produk khususnya cat dan thinner beserta mata rantai aktivitasnya secara integrasi dengan mendaya gunakan seluruh sumber daya secara efektif, efisien dan sinergis sehingga mampu meningkatkan pertumbuhan usaha untuk mencapai maksud dan tujuan perusahaan. CV. Catur Pandawa Maju Bersama ini melayani pemesanan cat dalam jumlah besar dan mendistribusikannya ke outletoutlet dan ke bengkel-bengkel. Terdapat beberapa permasalahan yang dihadapi di Catur Pandawa Maju Bersama yaitu sebagai berikut:

a. Dalam sistem penyajian informasinya masih belum terlalu efektif karena sistem dalam pengentrian datanya masih disimpan dalam bentuk berkas Microsoft Excel, sebagian datanya dicetak lalu diarsipkan ini dapat membuat data tersebut dapat terhapus jika komputer yang digunakan mengalami kerusakan dan data cetak tersebut sewaktu-waktu dapat hilang.

b. Dalam pencarian dan pengolahan datanya sering mempunyai kendala yaitu susahnya untuk menemukan file data yang telah disimpan sehingga ini memakan waktu yang cukup lama karena harus mencari secara manual bukan secara otomatis.

c. Selain itu dalam sistem persediaannya belum menerapkan metode Distribution Requirement planning (DRP), ini terbukti dalam proses persediaan barang belum optimal yang disebabkan tidak seimbangnya jumlah stok produk paint otomotif dengan banyaknya permintaan pemesanan.

d. Selain proses pembelian yang masih dilakukan secara manual yaitu barang masuk dan keluar masih tercatat dalam buku sehingga pada saat pimpinan meminta laporan penjualan, keuangan, dan transaksi pada kasir/ admin kantor harus merekapitulasi ulang terlebih dahulu sehingga baru mendapatkan hasil laporan.

\section{METODOLOGI PENELITIAN}

\subsection{Tinjauan Pustaka}

\subsubsection{Sistem Informasi}

Menurut (Pratama, 2014), sistem informasi merupakan gabungan dari empat bagian utama. Keempat bagian utama tersebut mencakup perangkat lunak (software), perangkat keras (hardware), infrastruktur, dan Sumber Daya Manusia (SDM) yang terlatih.

\subsubsection{Distribusi}

Menurut (Martono, 2015), Distribusi merupakan aktivitas pergerakan barang dan jasa dari pemasok hingga konsumen akhir melalui distribution channel (saluran distribusi).

\subsubsection{Metode DRP (Distribution Requirements Planning)}

Menurut (Gaspersz, 2004), istilah DRP memiliki dua pengertian yang berbeda, yaitu: Distribution Requirement Planning berfungsi menentukan kebutuhankebutuhan untuk mengisi kembali inventori pada Distribution Center (DC).

\subsubsection{DFD (Data Flow Diagram)}

Menurut (Sukamto, R. A., \& Shalahuddin, M., 2013), Data Flow Diagram (DFD) adalah representasi grafik yang menggambarkan aliran informasi dan transformasi informasi yang diaplikasikan sebagai data yang mengalir dari masukan (input) dan keluaran (output). 


\subsubsection{ERD (Entity Relationship Diagram)}

Entity Relation Modelling adalah sebuah pendekatan top-bottom dalam perancangan basis data, yang dimulai dengan mengidentifikasi data-data terpenting yang disebut dengan entitas, dan hubungan antara entitas-entitas tersebut yang menggambarkan dalam suatu model (Indrajani, 2014).

\subsubsection{MySQL}

Menurut (Nugroho, 2008), MySQL adalah software atau program aplikasi database, yaitu software yang dapat dipakai untuk menyimpan data berupa informasi, teks dan juga angka.

\subsubsection{Database}

Menurut (Sukamto, R. A., \& Shalahuddin, M., 2013), Sistem basis data adalah sistem terkomputerisasi yang tujuan utamanya adalah memelihara data yang sudah diolah atau informasi dan membuat informasi tersedia saat dibutuhkan.

\subsection{Metode Pengembangan Sistem.}

Metode pengembangan yang digunakan dalam Sistem Informasi Distribusi pada CV. Catur Pandawa Maju Bersama Palembang yaitu menggunakan model air terjun (waterfall) kadang dinamakan siklus hidup klasik (classic life cycle). Dimana hal ini menyiratkan pendekatan yang sistematis dan berurutan (sekuensial) pada pengembangan perangkat lunak, dan perangkat keras, yang dimulai dengan spesifikasi kebutuhan pengguna dan berlanjut melalui tahapan-tahapan perencanaan (planning), pemodelan (modeling), konstruksi (construction), serta penyerahan sistem/perangkat keras ke para pelanggan/pengguna (deployment).

\section{HASIL DAN PEMBAHASAN}

\subsection{Pemodelan}

\subsubsection{DFD Level 0}

Proses sistem yang diusulkan, pada sistem ini mempunyai entitas yaitu: entitas admin, entitas kasir, entitas pimpinan. Masing-masing entitas mempunyai aliran data, baik itu data masuk dan data keluar. Entitas admin mempunyai data masukan seperti: barang masuk, harga toko, master barang, kategori, data sales, data toko, dan data user. Entitas admin mempunyai data keluaran seperti: data toko, data sales, data user, kategori, harga toko dan barang keluar. Entitas kasir hanya mempunyai satu (1) data yaitu melakukan transaksi penjualan. Entitas kasir mempunyai data keluaran seperti: laporan transaksi. Entitas Pimpinan tidak mempunyai data masukan karena entitas-nya hanya melihat. Entitas Pimpinan mempunyai data keluaran seperti: laporan barang masuk, laporan barang keluar, laporan stok, laporan toko, laporan sales, laporan transaksi laporan penjualan, dan laporan keuangan. 


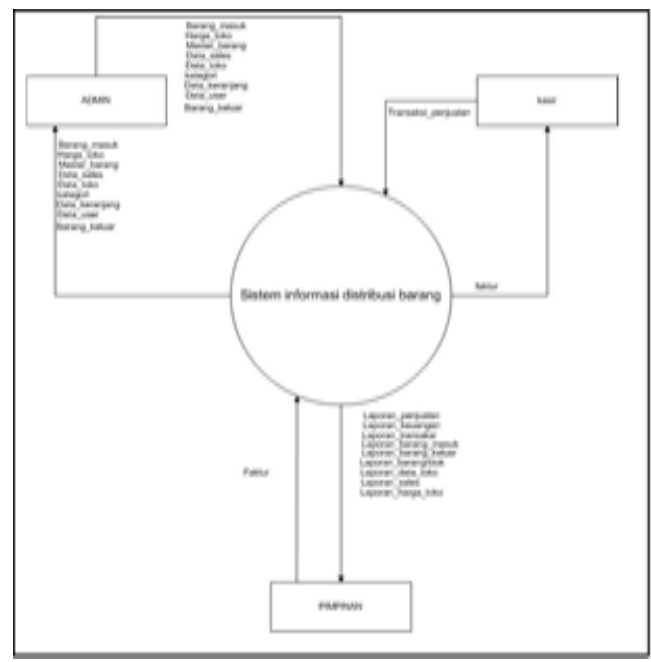

Gambar 1. DFD Level 0 Diusulkan

\subsubsection{DFD Level 1}

DFD Level 1 pada sistem informasi distribusi produk paint otomotif terdapat 8 aliran data di antara nya yaitu barang, barang masuk, barang keluar, harga toko, kategori, keranjang, sales, toko dan user. Proses-proses yang terdapat pada sistem baru yaitu mengelola data user, mengelola data toko, mengelola data sales, mengelola data keranjang, mengelola data kategori, mengelola data harga toko, mengelola data barang, mengelola data barang masuk, mengelola data barang keluar dan laporan. DFD sistem baru diatas, prosesproses yang terdapat pada sistem perencanaan dan pengendalian persediaan ini telah memiliki pengelolaan data yang disimpan ke tabel database, sehingga data-data yang dikelola saling berinteraksi dan dapat menghasilkan informasi.

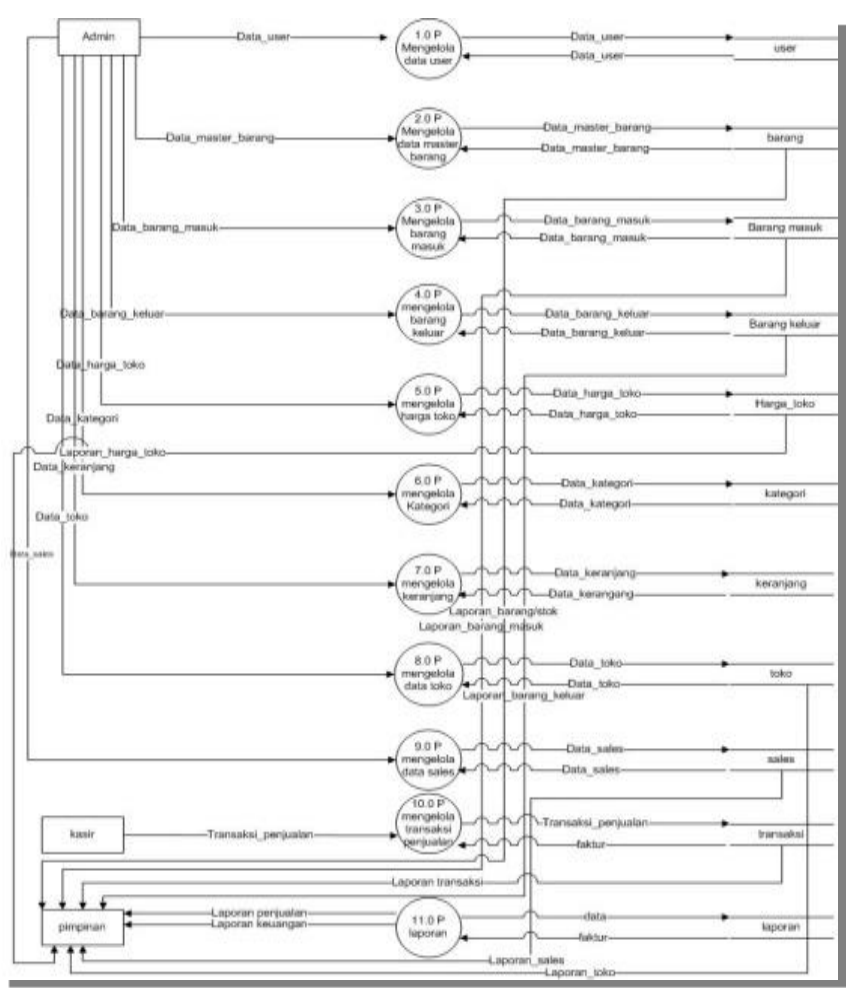

Gambar 2. DFD Level 1 


\subsection{Implementasi}

\subsubsection{Halaman Login}

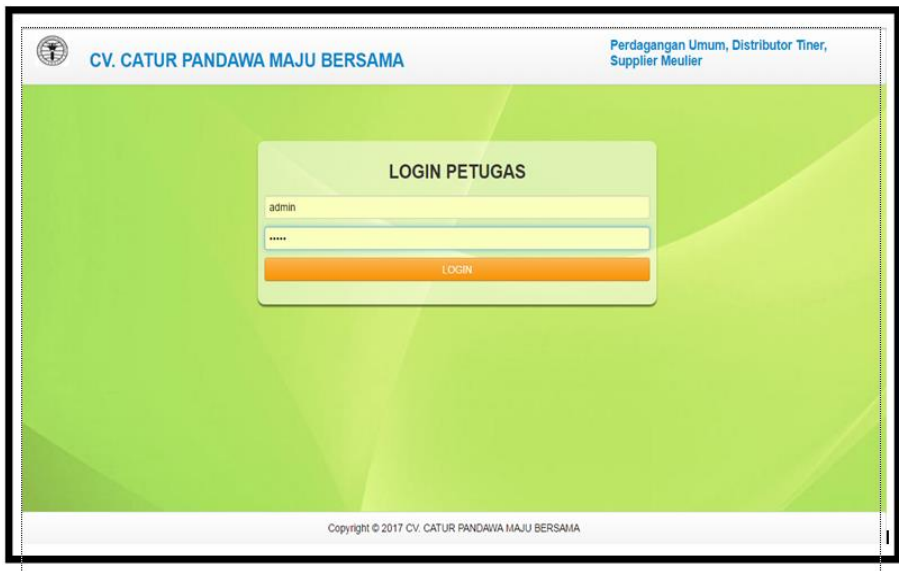

Gambar 3. Halaman Login

\subsubsection{Halaman Beranda}

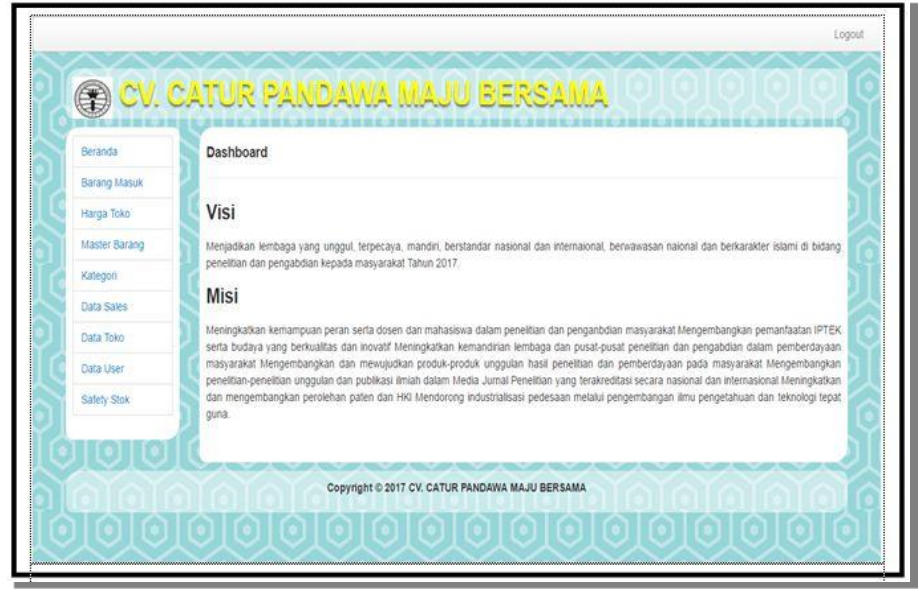

Gambar 4. Halaman Beranda

\subsubsection{Halaman Barang Masuk}

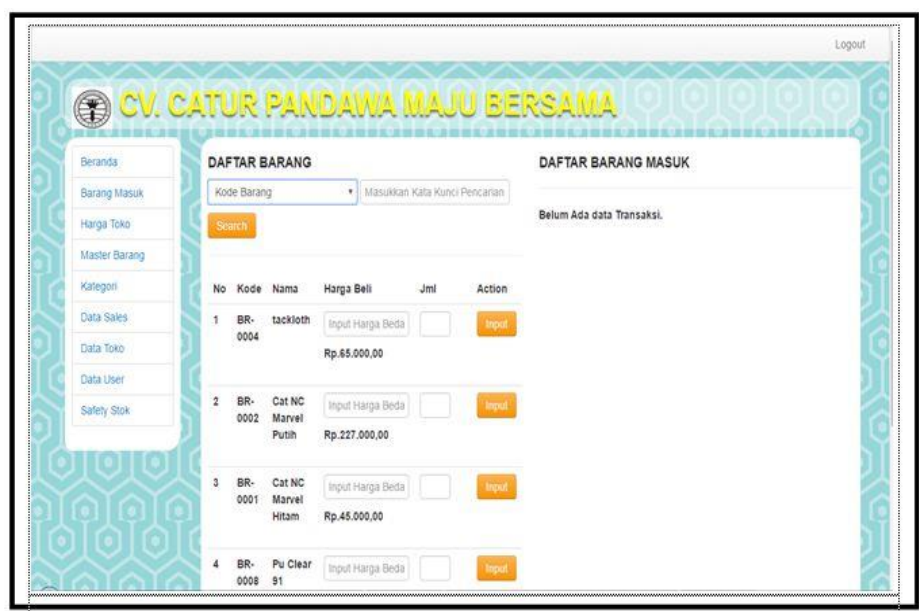

Gambar 5. Barang Masuk

JUSIFO (Jurnal Sistem Informasi), Volume 3, Nomor 2, Desember 2017 


\subsubsection{Halaman Tambah Harga Toko}

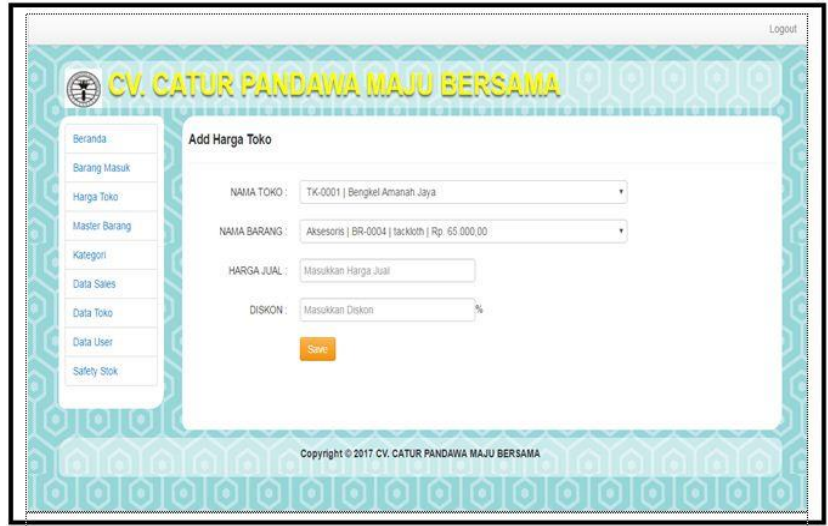

Gambar 6. Tambah Harga

\subsubsection{Halaman Manage Data Toko}

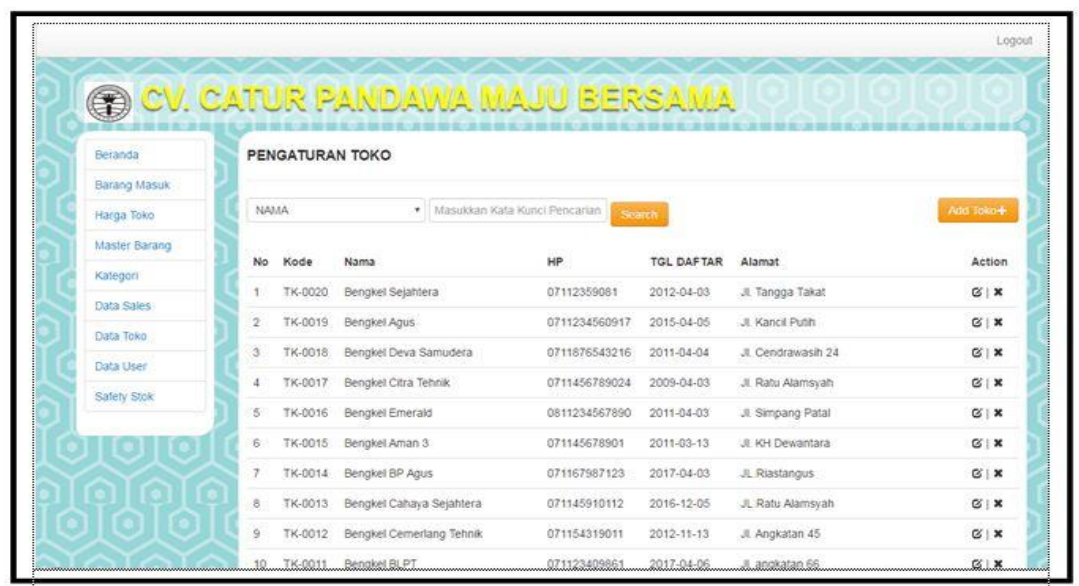

Gambar 7. Manage Data Toko

\section{KESIMPULAN}

Berdasarkan hasil analisis dan pembahasan sistem pada bab-bab sebelumnya, maka dapat disimpulkan sistem informasi distribusi produk paint otomotif menggunakan metode distribution requirement planning, menghasilkan berupa: Membangun sistem informasi distribusi produk paint otomotif menggunakan metode DRP (Distribution Requirements Planning) berbasis web (studi kasus: CV. Catur Pandawa Maju Bersama Palembang) akan sangat membantu perusahaan karena metode DRP (Distribution Requirements Planning) dapat memberikan kerangka kerja dalam manajemen distribusi inventory, yang berfungsi untuk menentukan kebutuhan-kebutuhan untuk mengisi kembali inventory pada cabang gudang. Sistem informasi distribusi yang dibangun menggunakan metode pengembangan sistem model air terjun (waterfall), PHP sebagai bahasa pemrograman, dan menggunakan pemodelan sistem Data Flow Diagram (DFD) karena sistem yang dirancang berstruktur dan dapat memberikan akses secara online kepada pengguna. 


\section{DAFTAR RUJUKAN}

Gaspersz, V. (2004). Production Planning and Inventory Control. Jakarta: Gramedia.

Indrajani. (2014). Database Systems Case Study All in One. Jakarta: PT. Elex Media Komputindo.

Martono, N. (2015). Metode Penelitian Sosial. Jakarta: PT. Rajagrafindo Persada.

Nugroho, B. (2008). Latihan Membuat Aplikasi Web PHP dan MySQL Dengan Dreamweaver MX. Yogyakarta: Gava Media.

Pratama, I. P. (2014). Sistem Informasi dan Implementasinya. Bandung: Informatika.

Sukamto, R. A., \& Shalahuddin, M. (2013). Rekayasa Perangkat Lunak Terstruktur dan Berorientasi Objek. Bandung: Informatika. 
142 | JUSIFO (Jurnal Sistem Informasi), p-ISSN: 2460-092X, e-ISSN: 2623-1662 